\title{
Coupling of Modelica Domestic Hot Water Simulation Model with Controller
}

\author{
Elisa Van Kenhove ${ }^{1, *}$, Lien De Backer ${ }^{2}$, Marc Delghust ${ }^{3}$, Jelle Laverge ${ }^{4}$ \\ 1,2,3,4 Ghent University, Faculty of Engineering and Architecture, \\ Department of Architecture and Urban Planning, Research Group of Building Physics \\ *Elisa.VanKenhove@UGent.be
}

\begin{abstract}
The energy needed for Domestic Hot Water (DHW) represents an important share in the total energy use of well-insulated and airtight buildings. One of the main reasons for this high energy demand is that DHW is produced at temperatures above $60^{\circ} \mathrm{C}$ to mitigate the risk of contaminating the hot water system with Legionella pneumophila. However, this elevated temperature is not necessary for most DHW applications, and has a negative effect on the efficiency of hot water production units. A Modelica simulation model has been developed that proposes an alternative to this constant $60^{\circ} \mathrm{C}$ by predicting the L. pneumophila concentration dynamically throughout the DHW system. Based on this knowledge, the topic of this paper is coupling the simulation model with a virtual DHW controller prototype. The DHW controller sets a comfortable DHW set point temperature in combination with heat shocks. The simulation model algorithm predicts the concentration of L. pneumophila present in the system, as this concentration cannot be measured in real time. When this predicted concentration passes a predefined threshold level, the controller will increase the set point temperature of the boiler (heat shock) in order to lower the concentration of L. pneumophila present until the predicted concentration is below a predefined boundary level. The energy savings by implementing the heat shock regime instead of the constant $60^{\circ} \mathrm{C}$ regime can be predicted with the simulation model. This new DHW controller is expected to become an important alternative for the current, energy intensive, constant high temperature tap water heating systems.
\end{abstract}

\section{Introduction}

\section{Motivation}

The energy needed for production, storage and distribution of Domestic Hot Water (DHW) represents an important share in the total energy use of well-insulated and airtight buildings. One of the main reasons for this high energy demand is that hot water is produced, stored and distributed at temperatures above $60^{\circ} \mathrm{C}$ to mitigate the risk of contaminating the hot water system with Legionella pneumophila, a bacteria that can cause an acute respiratory disease or severe pneumonia which can be fatal. At $60^{\circ} \mathrm{C}$, L. pneumophila growth is stopped and the remaining bacteria are killed. However, this elevated temperature is not necessary for most DHW applications, taking a shower and washing our hands requires a temperature of only $30-40^{\circ} \mathrm{C}$. The disparity between $60^{\circ} \mathrm{C}$ and $40^{\circ} \mathrm{C}$ doubles the temperature difference between hot water system and environment (around $20^{\circ} \mathrm{C}$ ) which has a negative effect on the storage and distribution losses and on the efficiency of hot water production units (such as heat pumps).

\section{Research question}

A simulation model has been developed that proposes an alternative to this constant $60^{\circ} \mathrm{C}$ by predicting the L. pneumophila concentration dynamically throughout the hot water system [1]. Based on this knowledge, a hot water controller is coupled to the simulation model that sets a lower hot water comfort temperature in combination with heat shocks when a predefined concentration limit has been reached. Simulation results of such a controller show savings of more than $35 \%$ on the hot water distribution energy use in an apartment building, without increasing contamination risk [2]. Additional production energy use savings, by implementing the controller in three different production units, namely an electric boiler, a heat pump boiler and a heat pump boiler with solar collectors, are going from respectively $14 \%$ to $64 \%$.

A theoretical proof of concept has been reached based on these simulation results. However, it is not sure whether the simulation model algorithms can run on a real controller (e.g. Arduino). The first steps in achieving this ultimate goal are investigated in this paper. An elaboration on the future steps will also be given.

\section{Background L. pneumophila}

The $60^{\circ} \mathrm{C}$ temperature limit has been established by investigating the growth dynamics of L. pneumophila bacteria in laboratory conditions and studying infection cases [3], [4], [5]. At these temperatures the DHW system is considered to be safe. Similarly, the Domestic Cold Water (DCW) temperature should be kept below $20^{\circ} \mathrm{C}$ to be considered L. pneumophila safe.

At temperatures below $20^{\circ} \mathrm{C}$, the bacteria become dormant but remain viable for months. The bacteria grow best at temperatures between $20^{\circ} \mathrm{C}$ and $45^{\circ} \mathrm{C}$ with an optimum around $35^{\circ} \mathrm{C}-41^{\circ} \mathrm{C}$. Beyond $45^{\circ} \mathrm{C}$, pasteurization starts and higher temperatures will 
eventually kill the organisms [6]. This can be seen on Figure 1A. On the $\mathrm{x}$-axes, the water temperature in degrees Celsius can be seen and on the y-axes, in Figure $1 B$, the time to double the number of L. pneumophila (mean generation time) and, in Figure $1 C$, the time to reach $90 \%$ reduction in cells (decimal reduction time). Figure $1 B$ is based on data from Yee and Wadowsky [7] from experiments on unsterilized tap water and Figure $1 C$ is based on data from laboratory experiments [3], [4], [5], [8], and is consistent with field data [9]. Figure $1 B$ shows that the time to double the number of $L$. pneumophila cells in water is less than half a day at $41^{\circ} \mathrm{C}$ and in Figure $1 C$ it can be noted that at $70^{\circ} \mathrm{C}, 90 \%$ of $L$. pneumophila in water gets killed in less than a minute.

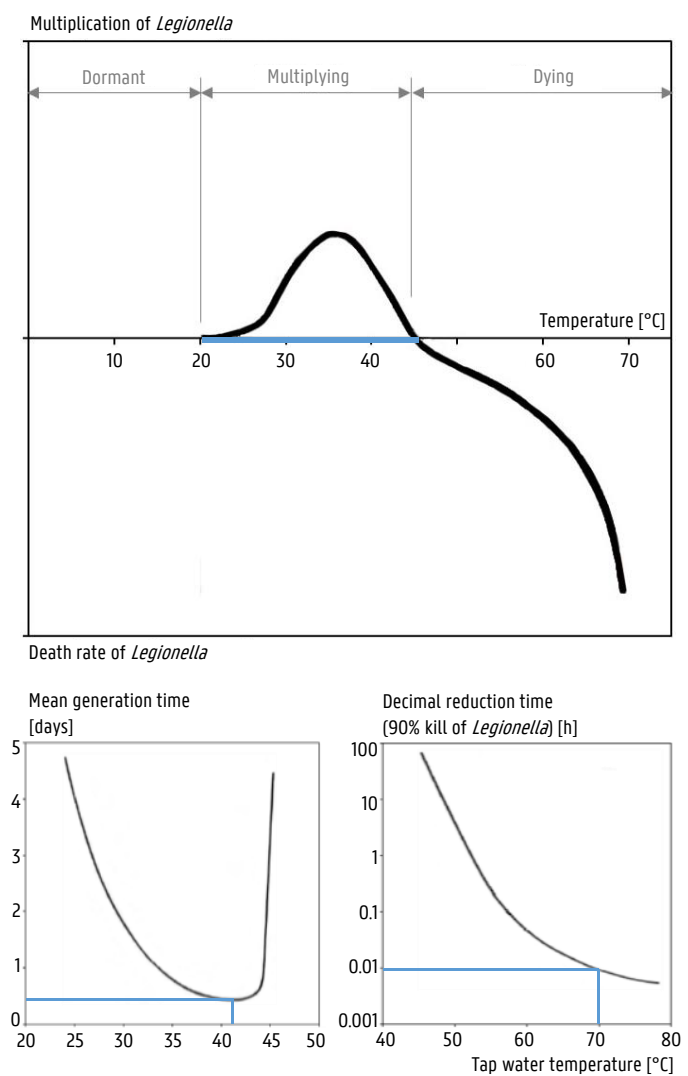

Figure 1: A. Growth function of L. pneumophila in water (adapted from [6]). B. An estimation of mean generation time (time to double the number of cells) of L. pneumophila in tap water (data from [7], adapted from [6]). $C$. The change in decimal reduction time (90\% reduction of L. pneumophila) with temperature (data from [3], [8], adapted from [6]).

\section{Methodology}

The aim of this paper is coupling a Modelica system simulation model with a virtual DHW controller prototype (Figure 2A). The operation of the controller can be compared with a heating thermostat, but instead it is controlling the set point temperature of the DHW boiler and in some cases the flow rate of the circulation pump of the DHW recirculation circuit. The simulation model algorithm predicts the concentration of L. pneumophila present at the taps (e.g. shower, kitchen sink), as this concentration cannot be measured real time. When this predicted concentration passes a predefined threshold level, the controller will increase the set point temperature of the boiler in order to lower the concentration of L. pneumophila present until the predicted concentration is below a predefined boundary level. An energy use optimisation process is part of the simulation model.

The focus of this paper is preparing for building the prototype of the controller. The hardware of this controller prototype will consist of a microprocessor unit (e.g. Arduino) running the algorithms on site, with potentially some additional peripherals (e.g. storage and communication modules for data collection during the testing phase or online updates).

In case the DHW set point temperature is controlled by a non-communicating thermostat (switch) and it can consequently only be adjusted manually on the heating element itself, the own developed controller will replace the existing control. In the other case, the boiler has the possibility to communicate with the own developed controller. In that case, the developed controller will set the water temperature using the communicating protocol. The communication protocol can be OpenTherm in certain cases or an alternative. OpenTherm is a standard which is not manufacturer-specific, enabling the straightforward coupling of the controlling device to different heat production appliances (e.g. boiler of type X, heat pump of type $\mathrm{Y}$, solar boiler of type Z).

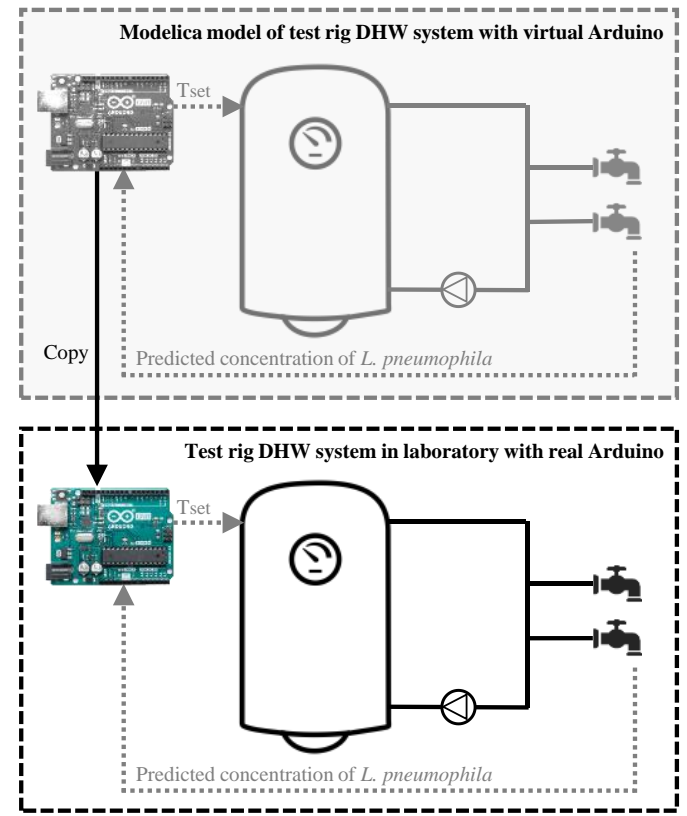

Figure 2: A. Virtual controller and test rig DHW simulation model. B. Real controller and test rig in laboratory.

In this paper, the controller is still driven from a computer. In future research, the algorithms of the simulation model will be simplified in order to be implemented in a real Arduino to test the operation of the controller. Subsequently, the prototype of the controller will be 
implemented in a basic setup of a DHW system, that will be built in laboratory conditions, to test the performance of the controller to achieve a technological proof of concept (Figure 2B).

Before performing the study in real conditions, a simulation study has been performed, that is part of this paper. Three simulation models of the test rig DHW systems have been developed. The difference between the three models is the DHW heat production unit. With these models a dynamic calculation has been performed, in order to test the algorithms on the microprocessor unit before building the hardware of the controller prototype. The controller should be able to control the temperature in the systems with a time based heat shock regime.

The development of the controller consists of different steps (Figure 3). In the first step, the hydraulic system is built in Modelica with the biological library. All the technical characteristics of the real boiler were used as input for the Modelica boiler component. This step is described in [10].

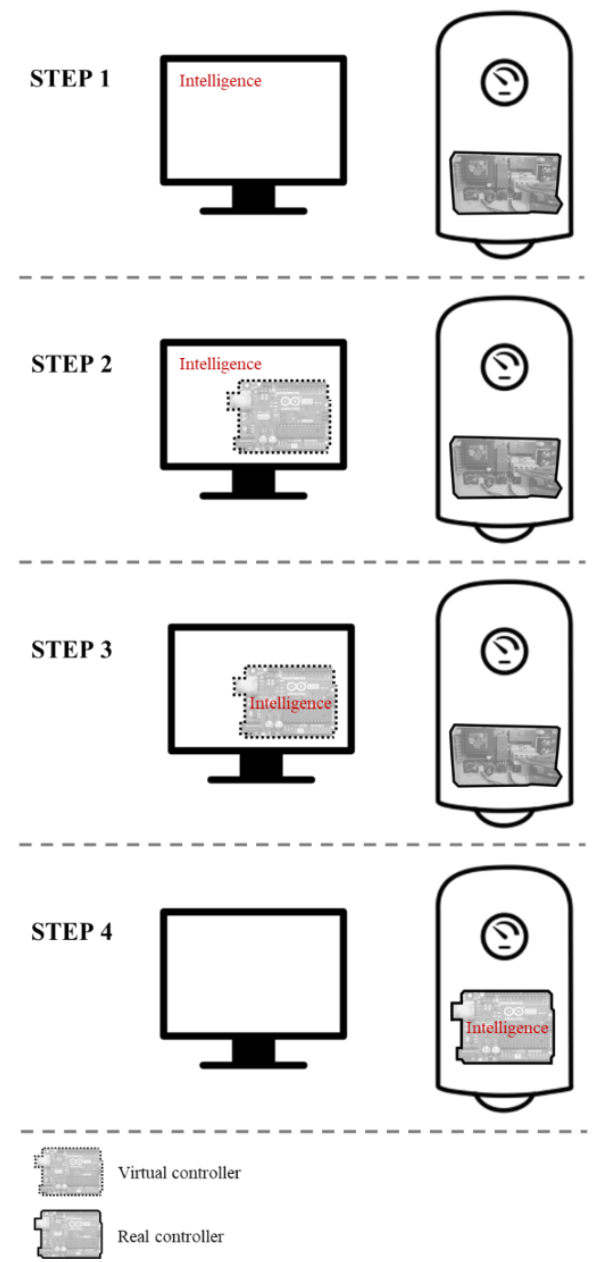

Figure 3: Work scheme of converting intelligence from Modelica model to controller in boiler.

In the second step (Figure 4), the virtual Arduino component from the Arduino library is used. This allows to implement the temperature control algorithms in a sketch file, which will be used later in the real controller. The virtual controller receives the temperature from a temperature sensor. For this, a Modelica component is developed that converts the temperature to an electrical signal. The L. pneumophila concentration calculation still happens in Modelica. In case the L. pneumophila concentration increases above the threshold value of $100 \mathrm{CFU} / \mathrm{L}$, a signal is sent to the virtual controller (pin D4) raising the set point temperature of the boiler to $65^{\circ} \mathrm{C}$. The output signal of the virtual Arduino is a $5 \mathrm{~V}$ signal. Since the Arduino operates at 5V, it cannot control the higher voltage immersion heater directly. Therefore, a $5 \mathrm{~V}$ relay is used to switch to 230 volt.

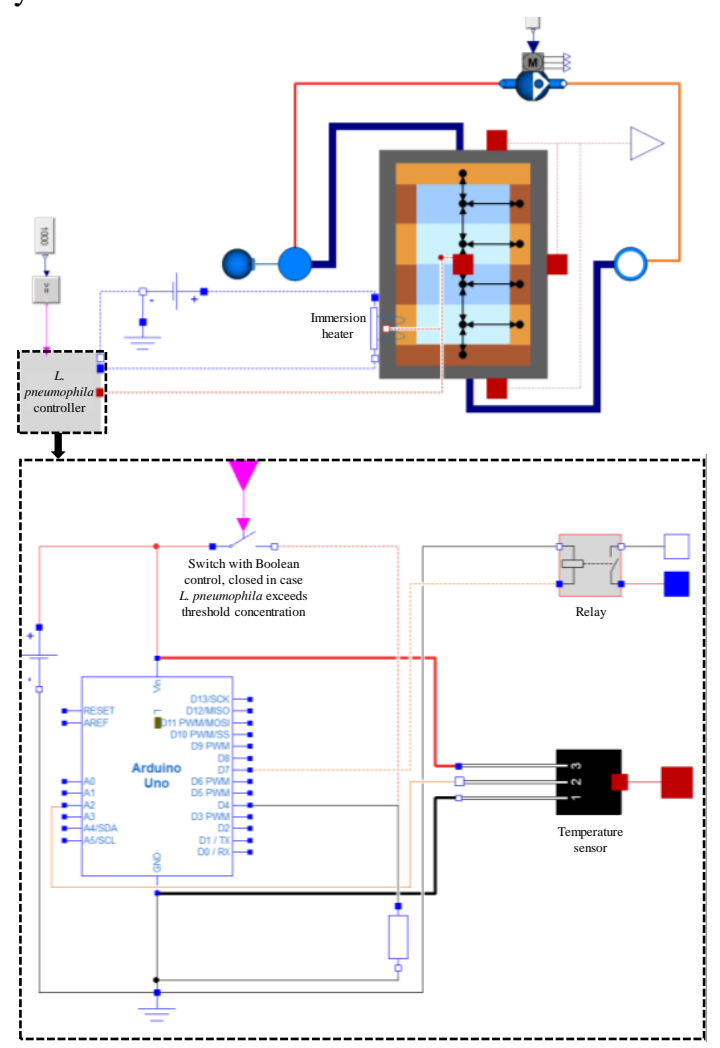

Figure 4: Principle of step 2, in case the Arduino controls the immersion heater directly (not through the communication protocol).

In the third step, the L. pneumophila concentration is no longer calculated in Modelica, but it is calculated in the sketch file of the virtual Arduino component. Meaning that the virtual controller has only one input, the water temperature in the bottom layer of the tank predicted by the temperature sensor component. A simplified function is used to predict the L. pneumophila concentration. This function is derived from the growth and starvation equation for L. pneumophila in water, as described in [1], in which a third degree piece-wise polynomial fitting technique (cubic hermite spline) is chosen to calculate the growth and death rate as is shown Figure 1. A separate spline function for L. pneumophila growth and starvation is developed. The predicted temperature in the bottom layer of the storage tank is used as input for this function. In future research, this function will be further optimised by finding a balance between the accuracy of the L. pneumophila concentration prediction, the calculation time and the limitations of the controller (RAM).

In step 4, that is part of future research, the real controller will be used. In a first step, it will also have only one input, 
i.e. the measured water temperature in the bottom layer of the tank.

\section{Modelling environment}

The Modelica language and Dymola (Dynamic Modelling Laboratory) environment is used to develop the models. The Modelica language is suitable for modelling various kinds of physical systems. It can handle large, complex multi-engineering models and is open to add user defined model components, such as the biological components that are required here. To model the hydraulic system, the Modelica 3.2.2 library, the Buildings 5.0.1 library [11] and IDEAS 2.0.0 library [12] has been used. To calculate the L. pneumophila concentration, a custom developed, by the authors, biologic library [2] has been used that makes it possible to predict the L. pneumophila growth. The virtual Arduino library [13] has been applied to build the virtual controller.

\section{Simulation model of three test rig DHW systems}

First of all, a Modelica model has been made of the complete laboratory system (Figure 5).

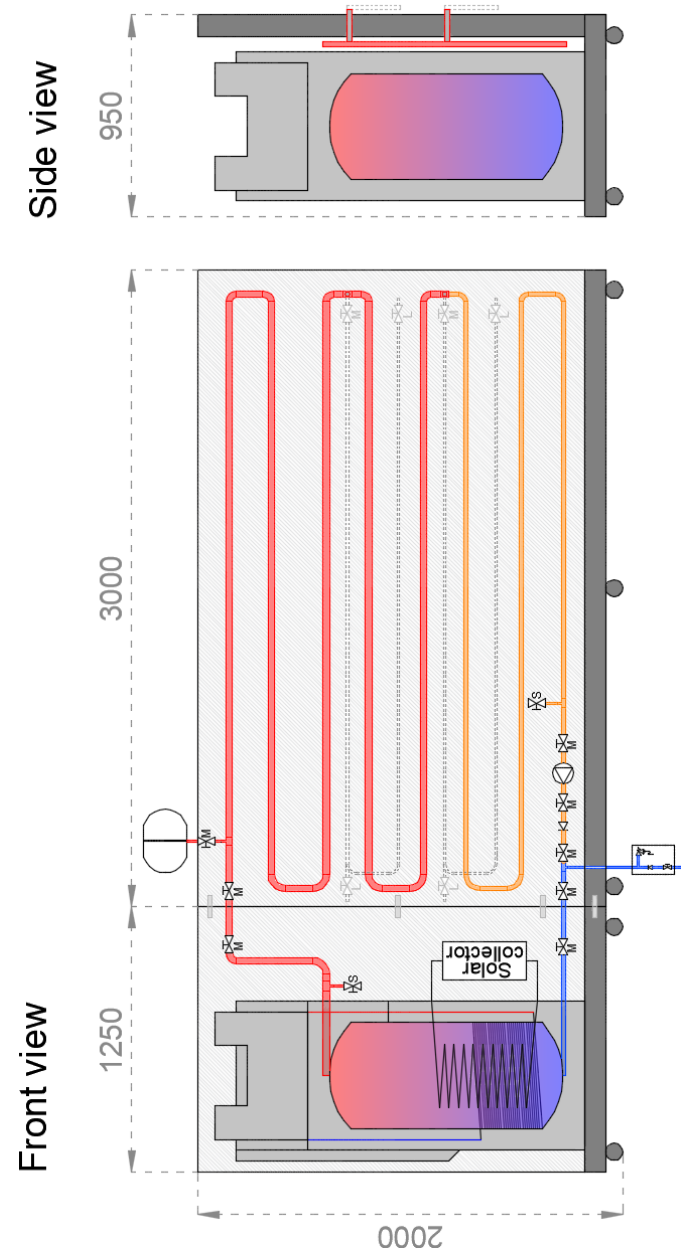

Figure 5: Test rig DHW system with heat pump boiler with solar collectors as production unit.

For all three production units, a different simulation model is made, including the distribution circuit and two distal pipes connected to two tap profiles corresponding with typical DHW kitchen and shower profiles of a single family household. In the next paragraphs, the different test rig DHW system components are being discussed.

\section{Production units}

Each production unit consists of a storage tank with a volume of $200 \mathrm{~L}$. The internal height of the tank is $1.5 \mathrm{~m}$ and the internal width is $0.4 \mathrm{~m}$. The tank is insulated with $10 \mathrm{~cm}$ of mineral wool with a thermal conductivity value of $0.04 \mathrm{~W} /(\mathrm{m} \cdot \mathrm{K})$. The water outlet is situated at the top. The water inlet (of return and cold water) is situated at the bottom of the tank.

The thermostat to control the water temperature is located at the bottom layer of the storage tank. To model the temperature in the storage tank, a one dimensional model is used that divides the height of the tank into several volumes (multi node approach), allowing to calculate the occurring temperature stratification. This is necessary because the growth of $L$. pneumophila is temperature dependent. By neglecting the stratification in the boiler, the death rate of the bacteria would be too high, leading to an underestimation of the corresponding health risks. The storage tank component used in the case study DHW system simulation model consists of eight layers. The six middle layers have a height of $0.1725 \mathrm{~m}$. The top (layer 1) and bottom layer (layer 8 ) have a height of $0.086 \mathrm{~m}$.

As mentioned before, three different DHW production units are compared. The base component used to model the storage tank will be the same. However, depending on the type of production unit, an additional heat exchanger and/or resistor has been added to the storage tank model. The power of the boiler is $3000 \mathrm{~W}$, in the first case this is provided by an electric immersion heater.

The component model used to simulate the storage tank is extended from the StratifiedEnhanced tank model, available in the Buildings 5.0.1 library. This component, as it is used in this paper, is updated by the authors in three ways [1].

- Addition of the possibility to vary the height of each volume segment.

- Addition of the possibility to choose different insulation thicknesses for the top, side and bottom of the tank.

- Addition of L. pneumophila growth equations to the thermohydraulic model.

\section{Distribution pipes}

The recirculation loop, connected to the tank, is $40 \mathrm{~m}$ long and consists of insulated multilayer pipes (Alpex). Characteristics of the pipes are retrieved from the technical ATG data sheet from the manufacturer [14].

Table 1 shows the characteristics of the recirculation loop and the distal pipes. The mass flow rate of the recirculation loop is calculated in such a way that a maximum temperature difference of $5^{\circ} \mathrm{C}$ between the 
supply and return temperature is achieved. This depends on the heat losses of the distribution system. With the 65$60^{\circ} \mathrm{C}$ temperature regime and a constant environmental temperature of $15^{\circ} \mathrm{C}$ (in shafts), this results in a mass flow rate of $0.14 \mathrm{~kg} / \mathrm{s}$. Accordingly, with a regime of $50-45^{\circ} \mathrm{C}$, this is $0.08 \mathrm{~kg} / \mathrm{s}$.

Table 1: Length and diameters of the distribution pipes.

\begin{tabular}{|l|c|}
\hline Supply recirculation pipe & \\
\hline Length [m] & 18.6 \\
\hline Outer diameter [m] & 0.032 \\
\hline Thickness pipe [m] & 0.003 \\
\hline Insulation [m] & 0.015 \\
\hline Heat loss coefficient [W/m·K] & 0.23 \\
\hline Return recirculation pipe & \\
\hline Length [m] & 21.4 \\
\hline Outer diameter [m] & 0.016 \\
\hline Thickness pipe [m] & 0.002 \\
\hline Insulation [m] & 0.015 \\
\hline Heat loss coefficient [W/m·K] & 0.17 \\
\hline Correction factor for thermal bridges [\%] & 20 \\
\hline Distal pipes & \\
\hline Length of one distal pipe [m] & 5.5 \\
\hline Insulation [m] & 0 \\
\hline
\end{tabular}

\section{Taps}

The required comfort temperature at the tap is $45^{\circ} \mathrm{C}$. This temperature can be reached with a mixing valve (threeway-valve) in case the production unit produces water at or above $60^{\circ} \mathrm{C}$ or by direct withdrawal if water with a temperature around $45^{\circ} \mathrm{C}$ is produced.

Table 2 shows the daily tap profile schedule used in the simulation model. The total tapped daily water volume is 211.40L. The volume flow rate at the taps (at $60^{\circ} \mathrm{C}$ ) is calculated based on DIN 1988-300 [15].

Table 2: Daily tap profile schedule.

\begin{tabular}{|r|l|c|c|c|}
\hline $\begin{array}{l}\text { Start } \\
\text { time } \\
\text { [hour] }\end{array}$ & $\begin{array}{l}\text { Draw-off } \\
\text { type } \\
{[-]}\end{array}$ & $\begin{array}{l}\text { Flow } \\
\text { rate } \\
{[\mathbf{l} / \mathbf{m i n}]}\end{array}$ & $\begin{array}{l}\text { Tap } \\
\text { duration } \\
{[\mathbf{s}]}\end{array}$ & $\begin{array}{l}\text { Tapped } \\
\text { volume } \\
{[\mathbf{L}]}\end{array}$ \\
\hline $6: 59$ & $\begin{array}{l}\text { Purge of the } \\
\text { shower/kitchen } \\
\text { pipe }\end{array}$ & 9.00 & 10 & 1.50 \\
\hline $7: 00$ & Shower & 9.00 & 355 & 53.25 \\
\hline $7: 10$ & Shower & 9.00 & 393 & 58.95 \\
\hline $8: 00$ & Shower & 9.00 & 296 & 44.40 \\
\hline $12: 00$ & Kitchen faucet & 4.20 & 6 & 0.42 \\
\hline $12: 30$ & Kitchen faucet & 4.20 & 20 & 1.40 \\
\hline $13: 45$ & Kitchen faucet & 4.20 & 30 & 2.10 \\
\hline $18: 15$ & Children's bath & 9.00 & 311 & 46.65 \\
\hline $19: 00$ & Kitchen faucet & 4.20 & 6 & 0.42 \\
\hline $19: 15$ & Kitchen faucet & 4.20 & 3 & 0.21 \\
\hline $20: 00$ & Kitchen faucet & 4.20 & 30 & 2.10 \\
\hline
\end{tabular}

\section{Controller components}

\section{Development board}

The first controller will be made with the development board Arduino Uno (Figure 6), this is an open-source microcontroller electronic platform based on the ATmega328P, featuring 14 digital input/output pins (of which 6 can be used as PWM outputs), 6 analogue inputs, a $16 \mathrm{MHz}$ quartz crystal, a USB connection, a power jack, an ICSP header and a reset button [16], [17]. Arduino executables can be a stand-alone process or can communicate with other processes, i.e. running processes on a PC.

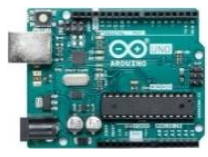

Figure 6: Arduino Uno Rev3 [17].

An Arduino library had been built for Modelica to test the Arduino virtually before configuring the hardware. With the Modelica Arduino library it is possible to simulate sketches (unit of code that is uploaded to and run on an Arduino board) on a virtual Arduino Uno, without the need for hardware, and connect the Modelica models to a real-world DHW system using the Firmata protocol [18]. Firmata is a generic protocol for communicating with the Arduino microcontroller from software on a host computer. The Arduino Uno model is driven by an ExternalObject that contains the compiled sketch and an implementation of the Arduino API. The external object is synchronized at every sample step with the Modelica model. When a model that contains the Arduino Uno block is translated the external object is automatically rebuilt [18].

\section{Power supply}

The Arduino Uno board will be powered with an external power supply (DC 5V).

\section{Immersive temperature Sensor (DS18B20)}

To measure the temperature, a 1-wire temperature sensor is used (Figure 7). This type of sensor provides calibrated digital temperature readings and is more tolerant of long wires between the sensor and the Arduino board [19]. The chip will be powered in normal mode.

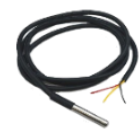

Figure 7: Immersive temperature sensor.

\section{Solid state relay}

In an electric boiler, the thermostat is built in and no communication port is present to overwrite this thermostatic control. Therefore, the original controller will be removed and replaced by the newly developed controller. This newly developed controller directly controls the immersion heater by a solid state relay (240VAC/25A) (Figure 8). 


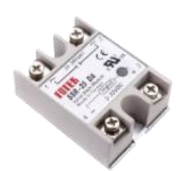

Figure 8: Solid state relay [20].

\section{Results}

In a first step, the simulation models of the hydraulic system consisting of a boiler, pump, pipes and taps have been made (Figure 9). A virtual Arduino controller component is made in Modelica Dymola and added to the simulation model to test the controller in simulations (Figure 10).

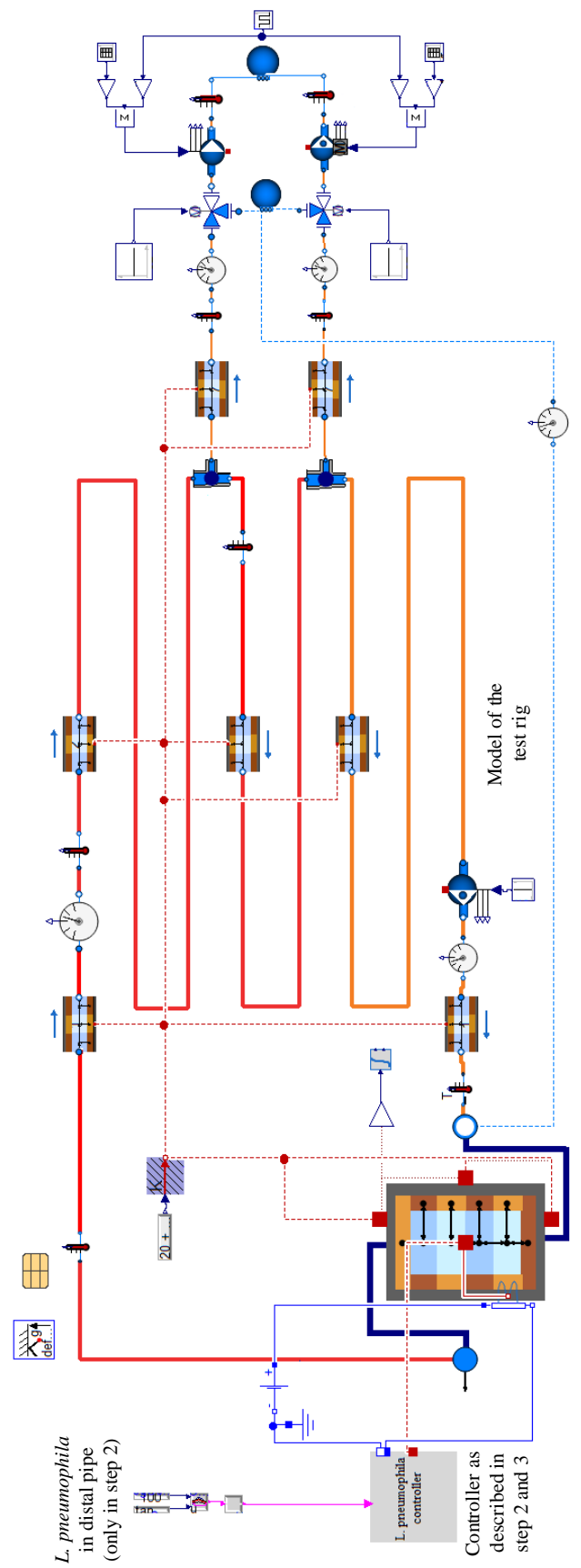

Figure 9: Virtual controller coupled to Modelica simulation model of test rig DHW system with electric boiler as production unit.
As can be seen in Figure 10, the effect of the temperature controller based on the predicted L. pneumophila concentrations is shown for step 1,2 and 3. As expected, in step 2, the virtual controller behaves nearly the same as in step 1 . The really small differences between step 2 and step 1 are due to the model of the temperature sensor in step 2, which transform the temperature of the storage tank into a voltage signal that can be interpreted by the Arduino. This difference in temperature causes also a difference in the predicted L. pneumophila concentration. The biggest error occurs during the heat shock. However, this small error in L. pneumophila concentration is almost zero after the heat shock due to the strong decrease of the L. pneumophila concentration during this heat shock.
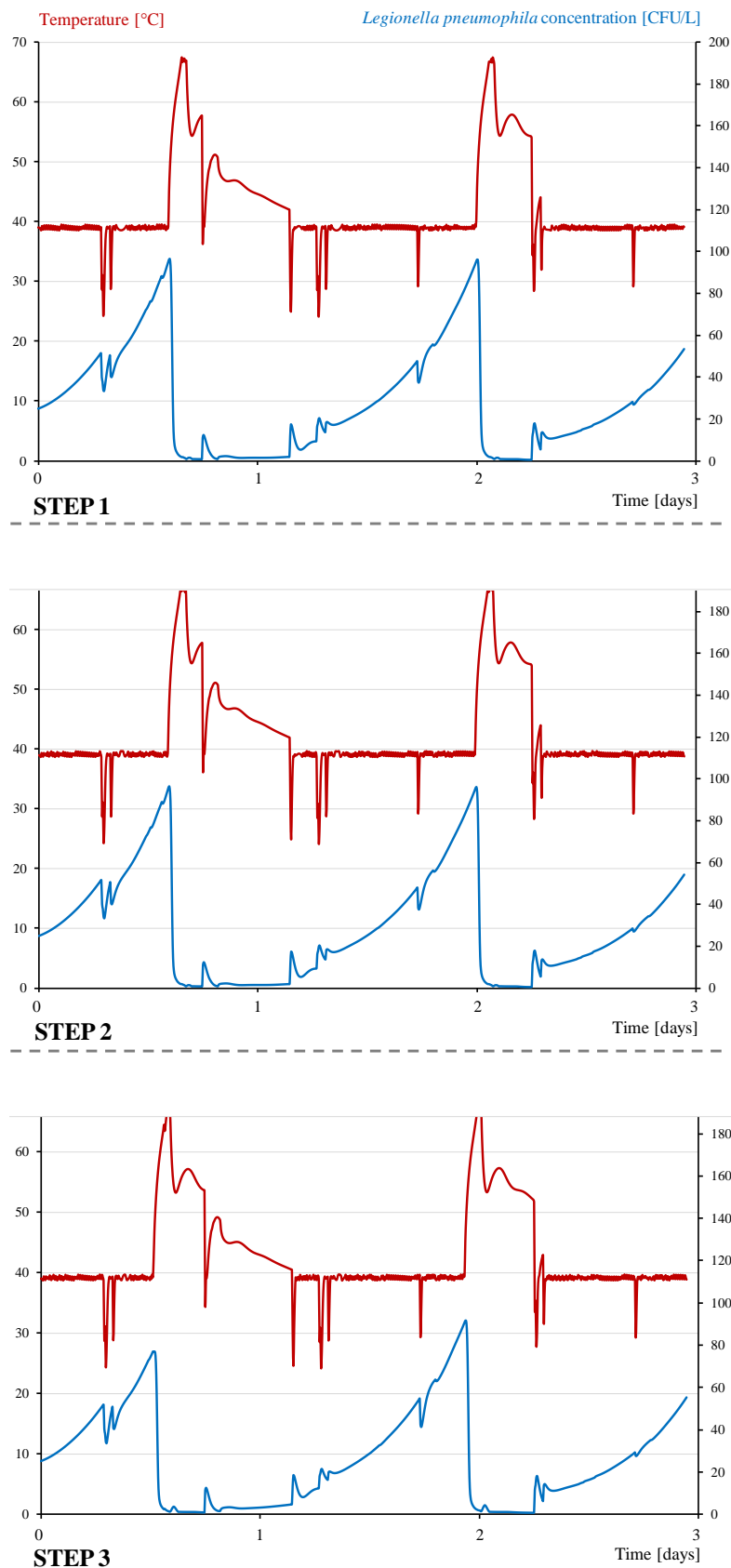

Figure 10: Temperature and L. pneumophila concentration in the storage tank (layer $7=$ bottom) in a. step 1, b. step 2 and c. step 3 . 
In the third step, the heat shocks do not take place at exactly the same time as in step 1 and step 2 . As can be observed in Table 3 and Figure 11, this leads to a larger Absolute Error (AE). The difference in time is due to the predicted L. pneumophila concentration that is no longer calculated in the Modelica model, but with a function based on the temperature in the bottom of the storage tank (layer 7) and the growth equation for L. pneumophila. This function is a simplification of the hydraulic model in Modelica, and it is chosen to overestimate, rather than underestimate the real concentration of L. pneumophila present as a safety precaution. Consequently, the threshold value of 100CFU/L will be exceeded faster than in step 1 and step 2 .

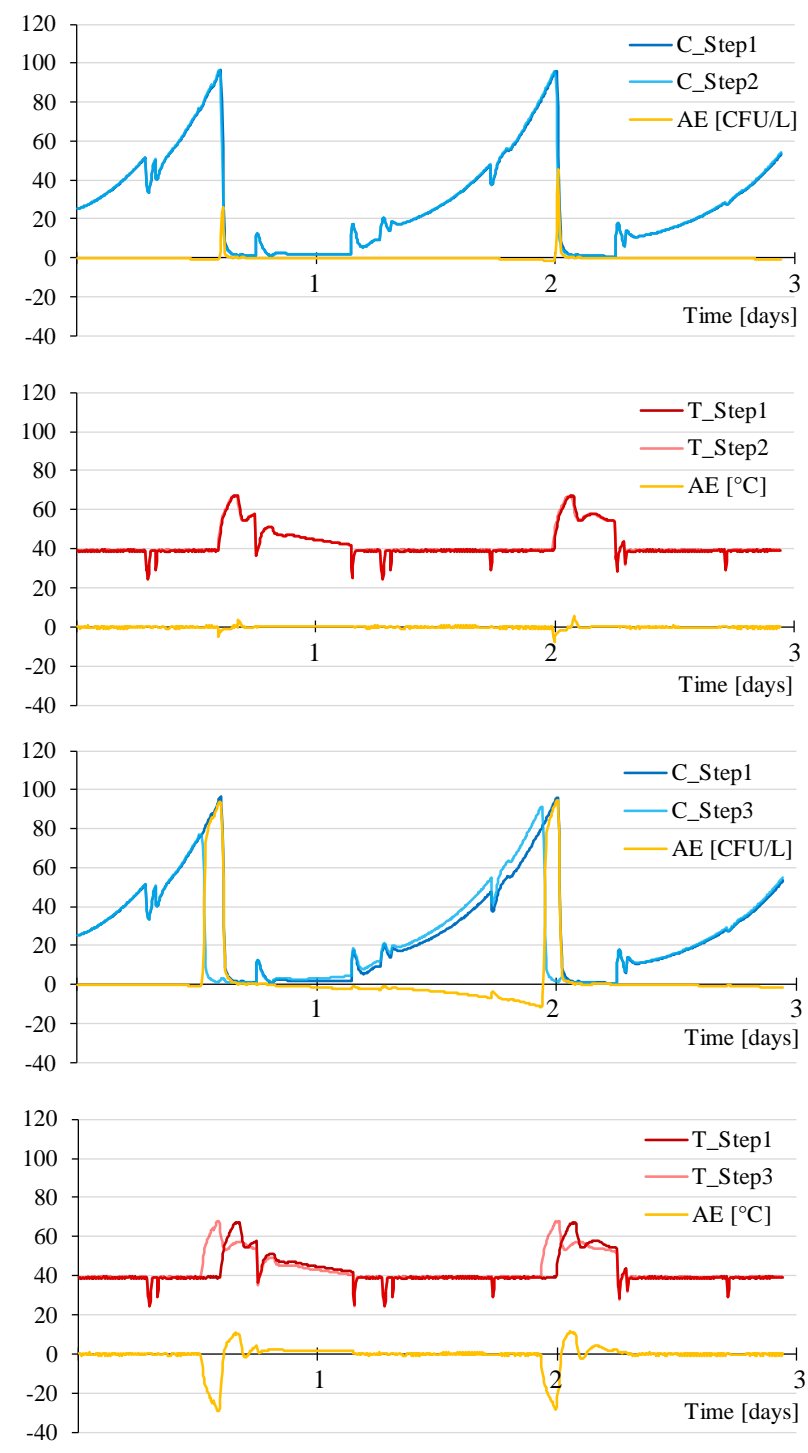

Figure 11: a. Comparison of predicted L. pneumophila concentration between step 1 and 2, $b$. Comparison of predicted temperature between step 1 and 2, $b$.

Comparison of predicted L. pneumophila concentration between step 1 and 3, c. Comparison of predicted temperature between step 1 and 3.
Table 3: Comparison of RMSE, MBE and CV(RMSE)

L. pneumophila concentration values of step 1, 2 and 3 .

\begin{tabular}{|l|c|c|c|}
\hline & $\begin{array}{c}\text { RMSE } \\
{[\mathrm{CFU} / \mathrm{L}]}\end{array}$ & $\begin{array}{c}\text { MBE } \\
{[\%]}\end{array}$ & $\begin{array}{c}\text { CV(RMSE) } \\
{[\%]}\end{array}$ \\
\hline Step 1 (base case) & 0 & 0 & 0 \\
\hline Step 2 versus Step 1 & 2.83 & 0.23 & 10.08 \\
\hline Step 3 versus Step 1 & 18.89 & 10.59 & 74.22 \\
\hline
\end{tabular}

\section{Discussion}

In a future step, it can be useful to use the predicted concentration of L. pneumophila in the distal pipes to regulate the controller. To make this possible it is necessary to send a signal to the controller when a tap occurs.

\section{Conclusion}

In this study, the possibility of a DHW controller prototype has been studied. This controller prototype includes an algorithm that predicts the L. pneumophila concentration present in the system, as this concentration cannot be measured in real time. Comparing the results of step 1, 2 and 3 shows that it is possible to run the algorithm on the virtual Arduino. The third step, which will be investigated further, shows similar predictions for temperature and $L$. pneumophila concentration as those of the first and second step, although a shift in time can be notices, i.e. the threshold value of 100CFU/L is reached faster. This new DHW controller is expected to become an important alternative for the current, energy intensive, constant high temperature tap water heating systems.

\section{Future research}

In future, the algorithms in the hydraulic Modelica Dymola simulation model will be simplified and replaced with $\mathrm{C}++$ code in order to be implemented in a real Arduino to test the operation of the controller. In this case the Arduino will predict the L. pneumophila concentration instead of the simulation model. The possible levels of simplification of the hydraulic simulation model will need to be analysed.

Subsequently, the prototype of the controller will be implemented in a basic setup of a DHW system, that will be built in laboratory conditions, to test the performance of the controller to achieve a technological proof of concept.

\section{Acknowledgement}

Funding details: This work is supported by the Industrial Research Fund (IOF) of Ghent University. The work that is the basis for this work (development of biological Modelica library) was supported by the Agency for Innovation by Science and Technology-Belgium (IWT/VLAIO) under Grant 141608. 


\section{Nomenclature}

AE

DCW

DHW

L. pneumophila

RMSE
Absolute Error

Domestic Cold Water

Domestic Hot Water

Legionella pneumophila

Root Mean Square Error

\section{References}

1. Van Kenhove, E., L. De Backer, A. Janssens and J. Laverge (2019). Simulation of Legionella Concentration in Domestic Hot Water: Comparison of Pipe and Boiler Models. Journal of Building Performance Simulation, 12(5), 595-619.

2. Van Kenhove, E. (2018). Coupled Thermohydraulic and biologic modelling of Legionella Pneumophila proliferation in domestic hot water systems, $\mathrm{PhD}$ thesis.

3. Stout, J.E., M.G. Best and V.L. Yu. (1986). Susceptibility of members of the family Legionellaceae to thermal stress: implication for heat eradication methods in water distribution systems. Ashrae Journal 46(5), 52-54.

4. Schulze-Röbbecke, R., M. Rodder and M. Exner. (1987). Multiplication and inactivation temperatures of naturally occurring legionellae. Zentralblatt für Bakteriologie, Mikrobiologie und Hygiene B184, 494500.

5. Sanden, G.N., B.S. Fields, J.M. Barbaree and J.C. Feeley. (1989). Viability of Legionella pneumophila in chlorine free water at elevated temperatures, Current Microbiology (18), 61-65.

6. Brundrett, G.W. (1992). Legionella and Building Services.

7. Yee, R.B. and R.M. Wadowsky. (1982). Multiplication of Legionella pneumophila in unsterilized tap water. Journal of Applied Environmental Microbiology (43), 1330-1334.

8. Dennis, P.J., D. Green and B.P.C. Jones. A note on the temperature tolerance of Legionella. Journal of Applied Bacteriology 56(2), 349-350.

9. Groothuis, D.G., H.R. Veenendaal and H.L. Dijkstra. (1985). Influence of temperature on the number of Legionella pneumophila in hot water systems. Journal of Applied Bacteriology (59), 529-536.

10. Van Kenhove, E., L. De Backer \& J. Laverge. (2019). Optimizing production efficiencies of hot water units using building energy simulations - Trade-off between
Legionella pneumophila contamination risk and energy efficiency. Proceedings from CLIMA2019: 13th REHVA HVAC World Congress. Bucharest (Ro), 26-29 May 2019.

11. Wetter M., W. Zuo, T.S. Nouidui and X. Pang. (2014). Modelica buildings library. Journal of Building Performance Simulation 7(4), 253-270.

12. Jorissen, F., G. Reynders, R. Baetens, D. Picard, D. Saelens, L. Helsen. (2018). Implementation and verification of the IDEAS building energy simulation library. Journal of Building Performance Simulation, 1-20.

13. Dassault Systèmes (released under GPLv3). (2018). https://github.com/CATIA-Systems/ModelicaArduino, updated in 2018, accessed on 15/01/2019.

14. ATG data sheet. (2015). http://www.butgb.be/content/technical_approval/dow nload.cfm/ATG2461_150921_N.pdf, updated on 21/09/2015, accessed on 15/01/2019.

15. Deutsches Institut Fur Normung E.V. (2012). Codes of practice for drinking water installations - Part 300: Pipe sizing; DVGW code of practice (DIN 1988-300).

16. Bonvini, M., F. Donida and A. Leva. (2009). Modelica as a design tool for hardware-in-the-loop simulation, Proceedings 7th Modelica Conference, Como (Italy), 20-22 September 2009.

17. Arduino home page. (2019). http://www.arduino.cc, updated in 2019, accessed on 15/01/2019.

18. Modelica-Arduino.

https://newsletter.modelica.org/2018-

01/index\#modelica-arduino-a-virtual-arduino-unoand-firmata-for-modelica, Modelica-Arduino, last updated in 2018, accessed on 15/01/2019.

19. The Arduino Playground. (2019). https://playground.arduino.cc, updated in 2019, accessed on 15/01/2019.

20. Solid State Relay. (2018). https://www.xcluma.com/solid-state-relay-modulessr-25da-25a-250v-3-32v-dc-input-24-380vacoutput, updated in 2018, accessed on 15/01/2019. 